\title{
Caracterização de nascentes pertencentes à Bacia Hidrográfica do Rio Turvo Limpo, MG
}

\author{
Mariana Barbosa Vilar ${ }^{1}$ \\ Vitor Hugo Breda Barbosa ${ }^{2}$ \\ Camila Soares Braga ${ }^{3}$ \\ Herly Carlos Teixeira Dias ${ }^{4}$ \\ Ana Paula Vilela Carvalho ${ }^{5}$ \\ 1,2,3,4,5 Universidade Federal de Viçosa - UFV \\ Cep: 36570-000 - Viçosa - MG, Brasil \\ ${ }^{1}$ maribvilar@hotmail.com; ${ }^{2}$ vitorhbb@yahoo.com.br; ${ }^{3}$ camilasbraga@yahoo.com.br; \\ herly@ufv.br; ${ }^{5}$ ana.vilela@ufv.br.
}

\begin{abstract}
The reduction of the drinking water offer and the hillsides and riparian zones deforestation alert the government organs and other institutions for the need of protecting the hydric resources. This way, the present study has aimed at monitoring the flow and qualifying the water of springs belonging to ten rural properties located in the Turvo Limpo River Watershed, MG. The flow measurements were accomplished during the period from September 2008 until June 2009. Due to the diversity of the characteristics of the studied springs, two methods of flow measurement were used: direct method through bucket and chronometer; and indirect method through a flow probe. The initial analyses of the water quality involved the turbidity, electric conductivity, $\mathrm{pH}$ and total coliforms parameters. The initial characterization of the ten springs demonstrated great diversity among them, because of the physical and biological factors and also because of the soil uses in the contribution areas of the same ones.
\end{abstract}

Key-words: forest hidrology, springs conservation, diagnosis.

Resumo. A redução na oferta de água potável, o desmatamento das encostas e das matas ciliares alertam os órgãos governamentais e outras instituições para a necessidade de se proteger os recursos hídricos. Desta forma, o objetivo do presente estudo é mensurar as vazões e qualificar a água de nascentes pertencentes a dez propriedades rurais localizadas na Bacia Hidrográfica do Rio Turvo Limpo, MG. As medições das vazões foram realizadas durante o período de setembro de 2008 a junho de 2009. Frente à diversidade das características das nascentes estudadas foram utilizados dois métodos de medição de vazão: método direto empregando-se balde e cronômetro; e método indireto através de um micromolinete. As análises iniciais da qualidade da água envolveram os parâmetros de turbidez, condutividade elétrica, potencial hidrogeniônico e coliformes totais. A caracterização inicial das dez nascentes demonstrou grande diversidade entre elas, em função dos fatores físicos, biológicos e dos usos do solo nas áreas de contribuição das mesmas.

Palavras-chave: hidrologia florestal, conservação de nascentes, diagnóstico.

\section{Introdução}

A conservação dos recursos hídricos, em termos da hidrologia das microbacias, da quantidade e da qualidade da água e do ecossistema aquático, depende do manejo dos ecossistemas. As mudanças de uso da terra podem alterar os serviços ambientais prestados pelos ecossistemas de inúmeras formas: desmatamento, expansão de fronteiras agrícolas, construção de estradas, urbanização e vários outros processos antrópicos de alteração da paisagem, que podem afetar os ciclos naturais da água e dos solos. Além disso, o manejo da terra, como o preparo do solo, plantio, adubação e colheita, podem afetar negativamente as propriedades hidrológicas dos solos, os quais, em médio e longo prazos, podem contribuir para a degradação das microbacias hidrográficas, afetando diretamente a qualidade e quantidade dos recursos hídricos, prejudicando os usuários ou consumidores de água. 
A utilização racional dos recursos naturais e a manutenção dos serviços ambientais são práticas inerentes ao Manejo Integrado de Bacias Hidrográficas. Esta é uma proposta educativa e técnica que visa recuperar o ambiente deteriorado através de atividades de proteção da natureza que possibilitam o uso sustentável dos recursos hídricos.

A bacia hidrográfica deve ser assumida como unidade básica de planejamento para o manejo sustentável dos recursos hídricos. Dentro dessa unidade de trabalho devem-se incluir as demandas locais e a necessidade de se reconhecer e incentivar produtores rurais anônimos que manejam adequadamente suas propriedades rurais contribuindo, portanto, para a sustentabilidade das bacias hidrográficas e para manutenção dos serviços ambientais.

Diante do exposto, o objetivo do presente estudo foi caracterizar dez nascentes localizadas na Bacia Hidrográfica do Rio Turvo Limpo, MG, através da medição das vazões e da qualidade da água dessas nascentes.

\section{Material e Métodos}

\subsection{Descrição da Área de estudo}

Este estudo foi realizado em dez propriedades rurais, das quais cinco se encontram na zona rural de Viçosa e as demais estão na zona rural de Porto Firme, em região limítrofe destes municípios com Guaraciaba, MG. As dez propriedades rurais amostradas para realização deste trabalho fazem parte do Projeto "Proteção de Nascentes" que é desenvolvido pelo Departamento de Engenharia Florestal da Universidade Federal de Viçosa, desde julho de 2005.

Em todas as propriedades rurais estudadas estão presentes nascentes que variam quanto à origem e vazão. Estas nascentes abastecem os Rios Turvo Sujo e Turvo Limpo (Figura 1) que são afluentes do Rio Doce, um dos principais rios do estado de Minas Gerais. De acordo com a Agência Nacional de Águas (ANA, 2009), a bacia do Rio Doce está localizada na Região Hidrográfica Costeira do Sudeste. A Bacia Hidrográfica do Rio Turvo Sujo é uma sub-bacia da Bacia Hidrográfica do Rio Turvo Limpo, e esta, por sua vez, é uma sub-bacia do Rio Piranga, um importante formador do Rio Doce.

A região apresenta relevo dominantemente forte ondulado e montanhoso (Domínio de Mar de Morros). O solo da região foi classificado como Latossolo Vermelho-Amarelo Distrófico e Cambissolo Distrófico (FERNANDES, 1996). De acordo com a classificação de Köppen, o clima da região enquadra-se no tipo Cwa (clima de inverno seco e verão chuvoso). Segundo Vianello e Alves (1991), a média anual pluviométrica de Viçosa é de 1.342,1 mm, com um período chuvoso de outubro a março e um período de estiagem de abril a setembro.

A caracterização das nascentes estudadas foi realizada através da avaliação das vazões dessas e da qualidade da água, adaptado-se a metodologia utilizada por Santos et al. (2007) que realizou uma análise hidrológica e socioambiental em uma bacia hidrográfica de ViçosaMG.

\subsection{Medições das Vazões}

As medições de vazão foram realizadas em pontos de captação de água das nascentes, durante o período de setembro de 2008 a junho de 2009. As vazões que caracterizaram o período chuvoso abrangeram o período compreendido entre os meses de outubro de 2008 a março de 2009. Para caracterização do período de estiagem foram coletados dados de vazão referentes aos meses de setembro de 2008; abril, maio e junho de 2009.

Utilizou-se o método direto de medição da vazão, empregando-se balde e cronômetro e, também, o método indireto através do micromolinete Flow Probe FP101. 


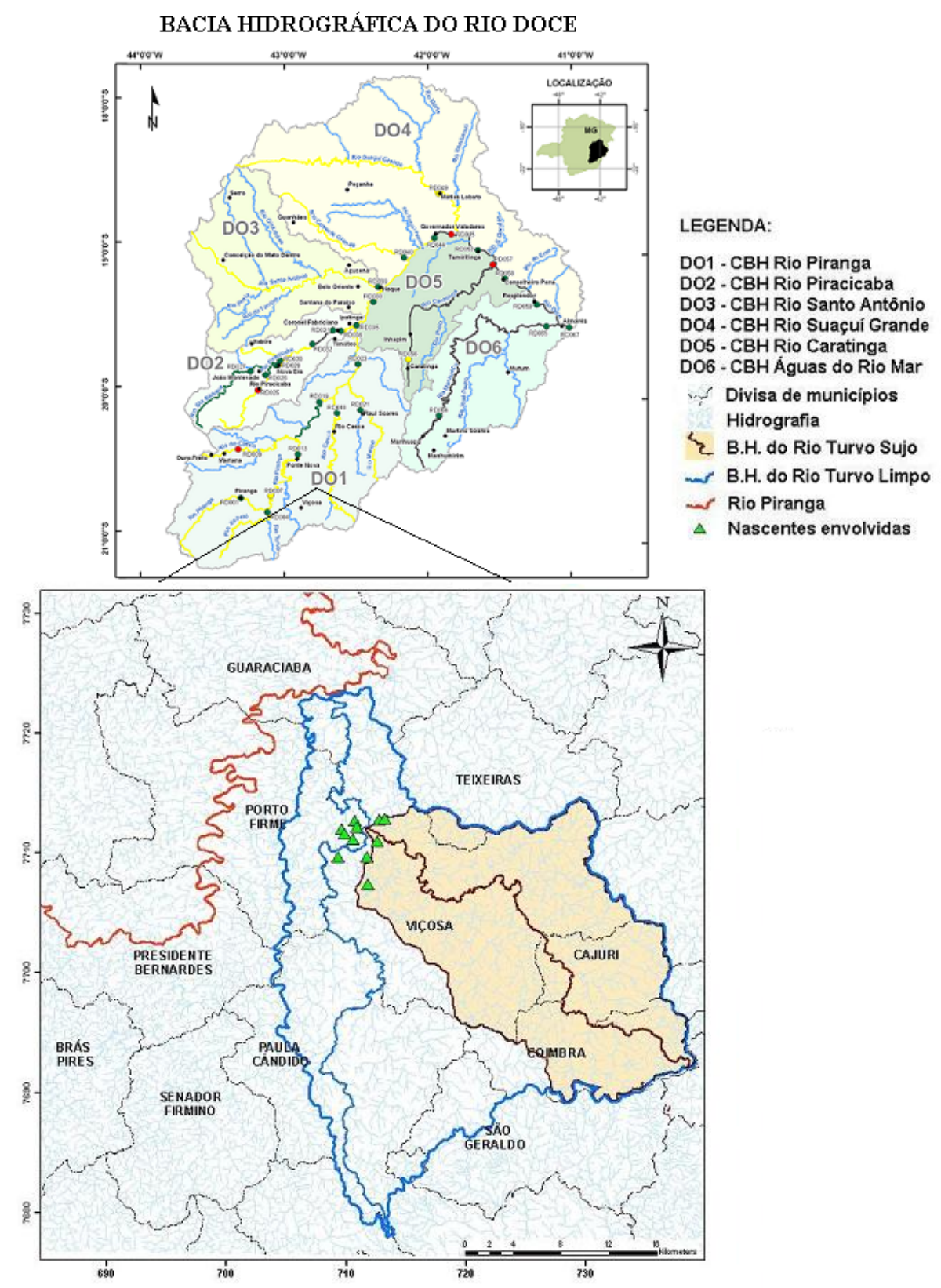

Figura 1 - Bacia Hidrográfica do Rio Doce com destaque para as bacias dos Rios Turvo Sujo e Turvo Limpo e para as nascentes envolvidas na pesquisa. Projeção: UTM, zona 23S. Datum: SAD 69.

\subsection{Qualidade da Água}

Para avaliação inicial da qualidade da água das nascentes estudadas foram utilizados quatro parâmetros:

- Condutividade elétrica foi medida através de um condutivímetro portátil de campo e laboratório, modelo DM-3P. A água de cada nascente foi coletada em frascos plásticos limpos e encaminhadas para o laboratório, onde foram realizadas as análises com auxílio do aparelho. Foram realizadas coletas mensais durante os meses de março, maio e junho de 2009.

- Turbidez foi medida através de um turbidímetro portátil de campo e laboratório, modelo DMTU. Amostras de água de cada nascente foram coletadas em frascos plásticos limpos. 
Em seguida, realizou-se a análise da turbidez em laboratório com auxílio do aparelho. Foram realizadas coletas mensais durante os meses de março, maio e junho de 2009.

- Potencial Hidrogeniônico da água das dez nascentes estudadas foi medido através de um pHmetro portátil de campo e laboratório, modelo DM-2P. Amostras de água das nascentes foram coletadas em frascos plásticos limpos e encaminhadas para laboratório onde o $\mathrm{pH}$ foi medido com o auxílio do aparelho. Foram realizadas coletas mensais durante os meses de março, maio e junho de 2009.

- Coliformes totais foram feitas junto ao Laboratório de Microbiologia de Alimentos da Universidade Federal de Viçosa. Foi coletada uma amostra de água por nascente. A amostra foi acondicionada em vidros esterilizados e transportada em caixa térmica com gelo reciclável para posterior análise em laboratório. As coletas das amostras de água foram realizadas nos mesmos locais onde foram medidas as vazões das nascentes, entretanto foram realizadas coletas individuais por nascente.

\section{Resultados e Discussões}

Durante o período chuvoso foram realizadas, em média, duas medições mensais por nascente, totalizando 67 medições. No período de janeiro e fevereiro as medições foram dificultadas pelo excesso de chuvas e pelo difícil acesso às propriedades rurais e, por isso, não foi possível acessar todas as nascentes neste período. Para o período de estiagem foram realizadas ao todo 32 medições. As vazões médias para o período chuvoso e para o período de estiagem, por propriedade, estão apresentadas nas Tabelas 1 e 2, respectivamente.

Tabela 1 - Vazões mensais e médias (L/s) do período chuvoso de nascentes localizadas em dez propriedades rurais da Bacia Hidrográfica do Rio Turvo Limpo, Viçosa/Porto Firme, MG

\begin{tabular}{|c|c|c|c|c|c|c|c|}
\hline \multirow{2}{*}{ Propriedade } & \multicolumn{3}{|c|}{ Ano 2008 } & \multicolumn{3}{c|}{ Ano 2009 } & \multirow{2}{*}{$\begin{array}{c}\text { Vazão } \\
\text { Múdia (L/s) }\end{array}$} \\
\cline { 2 - 7 } & Out. & Nov. & Dez. & Jan. & Fev. & Mar. & Méd \\
\hline 1 & & 1,77 & 4,89 & 10,19 & 9,74 & 9,26 & 7,17 \\
\hline 2 & 0,02 & 0,03 & 0,05 & 0,12 & 0,07 & 0,05 & 0,06 \\
\hline 3 & & 0,15 & 0,17 & 0,56 & 0,6 & 0,25 & 0,35 \\
\hline 4 & & 8,18 & 0,14 & 0,14 & 0,12 & 0,17 & 1,75 \\
\hline 5 & 4,74 & 5,02 & 5,52 & 12,43 & 17,49 & 18,54 & 10,62 \\
\hline 6 & 0,12 & 0,12 & 0,11 & 0,12 & 0,11 & 0,11 & 0,12 \\
\hline 7 & & 2,67 & 2,2 & - & 6,61 & 3,4 & 3,72 \\
\hline 8 & 0,57 & 0,74 & 0,87 & - & 1,73 & 1,38 & 1,06 \\
\hline 9 & 0,22 & 0,27 & 0,3 & 0,73 & 0,9 & 0,6 & 0,50 \\
\hline 10 & & 0,16 & 0,12 & 0,25 & 0,15 & 0,24 & 0,18 \\
\hline $\begin{array}{c}\text { Precipitação } \\
\text { Viçosa (mm) }\end{array}$ & 67,5 & 245,2 & 685,1 & 287,9 & 126,8 & 256,4 & 278,15 \\
\hline $\begin{array}{c}\text { Precipitação Porto } \\
\text { Firme (mm) }\end{array}$ & 67,5 & 271,9 & 420,5 & 284,1 & 162,3 & 198,9 & 234,2 \\
\hline
\end{tabular}

Os valores resultantes da avaliação da condutividade elétrica da água das nascentes amostradas na Bacia Hidrográfica do Rio Turvo Limpo podem ser visualizados na Tabela 3. Este parâmetro fornece uma boa indicação das modificações na composição de uma água, especialmente na sua concentração mineral, mas não fornece nenhuma indicação das 
quantidades relativas dos vários componentes. À medida que mais sólidos dissolvidos são adicionados, a condutividade da água aumenta. Altos valores podem indicar características corrosivas da água (IGAM, 2008). O ano hidrológico considerado foi atípico para a região visto que no mês de abril foram registradas chuvas significativas para ambos municípios de Viçosa e Porto Firme, MG.

Tabela 2 - Vazões mensais e médias (L/s) do período de estiagem de nascentes localizadas em propriedades rurais da Bacia Hidrográfica do Rio Turvo Limpo, Viçosa/Porto Firme, MG

\begin{tabular}{|c|c|c|c|c|c|}
\hline \multirow{2}{*}{ Propriedade } & Ano 2008 & \multicolumn{3}{|c|}{ Ano 2009 } & Vazão \\
\cline { 2 - 5 } & Set. & Abr. & Mai. & Jun. & Média (L/s) \\
\hline 1 & & 9,33 & 4,34 & 3,82 & 5,83 \\
\hline 2 & 0,016 & 0,05 & 0,06 & 0,05 & 0,04 \\
\hline 3 & & 0,37 & 0,16 & 0,17 & 0,23 \\
\hline 4 & & 0,22 & 0,22 & 0,15 & 0,19 \\
\hline 5 & & 19,44 & 18,83 & 8,46 & 15,58 \\
\hline 6 & & 0,11 & 0,11 & 0,11 & 0,11 \\
\hline 7 & 0,65 & 4,68 & 2,87 & 1,43 & 2,99 \\
\hline 8 & & 0,64 & 0,46 & 0,36 & 0,49 \\
\hline 9 & 100 & 110,3 & 14,2 & 62,6 & 71,78 \\
\hline 10 & 80 & 106,4 & 19,5 & 56,7 & 65,65 \\
\hline $\begin{array}{c}\text { Precipitação Viçosa } \\
\text { (mm) }\end{array}$ & & 0,16 & 0,18 & 0,17 & 0,17 \\
\hline $\begin{array}{c}\text { Precipitação Porto } \\
\text { Firme (mm) }\end{array}$ & & 12,90 & 0,90 & 17 \\
\hline
\end{tabular}

Tabela 3 - Condutividade elétrica da água das nascentes amostradas na Bacia Hidrográfica do Rio Turvo Limpo, Viçosa/Porto Firme, MG. 2009

\begin{tabular}{|c|c|c|c|c|}
\hline \multirow{2}{*}{ Propriedade } & \multicolumn{4}{|c|}{ Condutividade Elétrica $\left(\boldsymbol{\mu S} / \mathbf{c m ~ a ~ 2 5}^{\mathbf{}} \mathbf{C}\right)$} \\
\cline { 2 - 5 } & Março & Maio & Junho & Média $^{*}$ \\
\hline 1 & 28,6 & 24,6 & 27,7 & 27,0 \\
\hline 2 & 11,4 & 22,9 & 64,7 & 33,0 \\
\hline 3 & 74,8 & 11,7 & 27,3 & 37,9 \\
\hline 4 & 12,7 & 68 & 11,9 & 30,9 \\
\hline 5 & 18,3 & 47,7 & 49,4 & 38,5 \\
\hline 6 & 110,3 & 93,2 & 27,3 & 76,9 \\
\hline 7 & 47,4 & 11,7 & 12,0 & 23,7 \\
\hline 8 & 40,6 & 56,8 & 35,7 & 44,4 \\
\hline 9 & 28,8 & 44,9 & 54,1 & 42,6 \\
\hline 10 & 54,4 & 57,8 & 27,2 & 46,5 \\
\hline Precipitação Viçosa (mm) & 256,4 & 14,2 & 62,6 & 111,1 \\
\hline & 198,9 & 19,5 & 56,7 & 91,7 \\
\hline
\end{tabular}

Percebe-se que existe variação entre os dados de condutividade coletados no final do período chuvoso e durante o período de estiagem. A precipitação pode carrear uma maior 
quantidade de íons aos cursos d'água e isto influencia diretamente a condutividade elétrica da água. Nota-se que no mês de junho, devido aos eventos pluviométricos, foram constatados aumento nos valores de condutividade em $60 \%$ das nascentes estudadas.

Os valores encontrados para a turbidez das nascentes estudadas (Tabela 4) não foram superiores a 40 UNT, com exceção da propriedade 10 que apresentou valor de 66,4 UNT em março de 2009.

Tabela 4 - Turbidez da água das nascentes amostradas na Bacia Hidrográfica do Rio Turvo Limpo, Viçosa/Porto Firme, MG. 2009

\begin{tabular}{|c|c|c|c|c|}
\hline \multirow{2}{*}{ Propriedade } & \multicolumn{4}{|c|}{ Turbidez (UNT) } \\
\cline { 2 - 5 } & Março & Maio & Junho & Média \\
\hline 1 & 20,4 & 18,3 & 18,0 & 18,9 \\
\hline 2 & 2,8 & 2,5 & 4,1 & 3,1 \\
\hline 3 & 7,7 & 25,6 & 35,3 & 22,9 \\
\hline 4 & 0,4 & 0,5 & 0,6 & 0,5 \\
\hline 5 & 13,3 & 7,9 & 10,8 & 10,7 \\
\hline 6 & 0,7 & 1,7 & 35,3 & 12,6 \\
\hline 7 & 2,9 & 25,6 & 4,7 & 11,1 \\
\hline 8 & 6,5 & 9,7 & 23,5 & 13,2 \\
\hline 9 & 1,0 & 1,7 & 2,1 & 1,6 \\
\hline 10 & 66,4 & 33,1 & 14,5 & 38,0 \\
\hline Precipitação Viçosa (mm) & 256,4 & 14,2 & 62,6 & 111,1 \\
\hline Precipitação Porto Firme (mm) & 198,9 & 19,5 & 56,7 & 91,7 \\
\hline
\end{tabular}

A precipitação no mês de junho foi atípica para Viçosa e Porto Firme. Isto pode ter influenciado o aumento nos valores de turbidez observados para $70 \%$ das nascentes estudadas no período considerado como estiagem (maio e junho).

Avaliando-se apenas o parâmetro de turbidez, 90\% das nascentes estudadas estariam enquadradas na classe 1 , conforme a Resolução $\mathrm{N}^{\circ} 357$ do CONAMA, podendo ser destinadas ao consumo humano após tratamento simplificado. Seguindo o enquadramento dos corpos d'água previsto nesta mesma resolução, a nascente localizada na propriedade 10 seria enquadrada na classe 2 .

Os valores de $\mathrm{pH}$ obtidos nos diferentes pontos de amostragem variaram entre 5,6 e 9,9 (Tabela 5). Percebe-se um aumento no potencial hidrogeniônico de $90 \%$ das nascentes estudadas quando se compara os valores observados nos meses de maio e junho. Isto pode ser explicado pelo elevado contingente pluviométrico que ocorreu atipicamente nos municípios de Viçosa e Porto Firme durante o mês de junho.

Conforme o laudo apresentado pelo Laboratório de Microbiologia de Alimentos, as análises das águas coletadas nas dez nascentes amostradas indicaram que estas se encontram em desacordo com o padrão microbiológico previsto na Portaria $n^{\circ} 518$ de 2004 do Ministério da Saúde. Esta portaria prevê a ausência de coliformes totais em $100 \mathrm{~mL}$ da amostra, como padrão de água a ser utilizada para o consumo humano (Tabela 6).

Segundo IGAM (2008), o monitoramento da qualidade da água do Rio Piranga em uma estação de amostragem em Porto Firme (Latitude: $-20^{\circ} 40^{\prime} 19^{\prime}$ '; Longitude: $-43^{\circ} 05^{\prime} 31^{\prime \prime}$ ), realizado em 2007, indicou um número mais provável (NMP) de 8.175 coliformes totais em $100 \mathrm{~mL}$. Portanto, as nascentes amostradas apresentam valores de coliformes totais inferiores àqueles obtidos para o Rio Piranga que tem como importante tributário, o Rio Turvo Limpo. Mesmo inferiores, estes valores de coliformes totais encontrados nas nascentes da Bacia 
Hidrográfica do Rio Turvo Limpo devem ser motivo de preocupação dos proprietários rurais e dos órgãos governamentais.

Tabela 5 - Potencial Hidrogeniônico $(\mathrm{pH})$ da água das nascentes amostradas na Bacia Hidrográfica do Rio Turvo Limpo, Viçosa/Porto Firme, MG. 2009

\begin{tabular}{|c|c|c|c|c|}
\hline \multirow{2}{*}{ Prop riedade } & \multicolumn{4}{|c|}{ Potencial Hidrogeniônico (pH) } \\
\cline { 2 - 5 } & Março & Maio & Junho & Média \\
\hline 1 & 9,4 & 7,8 & 9,6 & 9,0 \\
\hline 2 & 8,0 & 7,7 & 9,0 & 8,2 \\
\hline 3 & 6,5 & 7,2 & 9,1 & 7,6 \\
\hline 4 & 5,6 & 6,6 & 6,5 & 6,2 \\
\hline 5 & 5,8 & 7,2 & 8,5 & 7,2 \\
\hline 6 & 7,1 & 6,4 & 9,1 & 7,5 \\
\hline 7 & 8,1 & 7,5 & 9,9 & 8,5 \\
\hline 8 & 8,4 & 6,9 & 8,9 & 8,1 \\
\hline 9 & 9,9 & 7,5 & 9,0 & 8,8 \\
\hline 10 & 8,1 & 7,5 & 9,2 & 8,3 \\
\hline Precipitação Viçosa (mm) & 256,4 & 14,2 & 62,6 & 111,1 \\
\hline Precipitação Porto Firme (mm) & 198,9 & 19,5 & 56,7 & 91,7 \\
\hline
\end{tabular}

Tabela 6 - Coliformes totais presentes na água de dez nascentes amostradas na Bacia Hidrográfica do Rio Turvo Limpo, Viçosa/Porto Firme, MG. 2009

\begin{tabular}{|c|c|}
\hline Propriedade & Coliformes Totais (NMP* em 100mL) \\
\hline 1 & $5,4 \times 10^{2}$ \\
\hline 2 & $1,6 \times 10^{3}$ \\
\hline 3 & $1,6 \times 10^{3}$ \\
\hline 4 & 4,0 \\
\hline 5 & $>1,6 \times 10^{3}$ \\
\hline 6 & $6,2 \times 10^{2}$ \\
\hline 7 & $2,4 \times 10^{2}$ \\
\hline 8 & 49,0 \\
\hline 9 & $1,6 \times 10^{3}$ \\
\hline 10 & $5,4 \times 10^{2}$ \\
\hline
\end{tabular}

A quantidade e qualidade da água das nascentes de uma bacia hidrográfica podem ser alteradas por diversos fatores, destacando a declividade, o tipo de solo e o uso da terra, principalmente das áreas de recarga, pois influenciam no armazenamento da água subterrânea e no regime da nascente e dos cursos d'água. Assim, o estudo das interações dos recursos naturais e das ações antrópicas na bacia hidrográfica é muito importante, uma vez que a conservação dos recursos hídricos não pode ser alcançada independentemente da conservação dos outros recursos naturais.

A caracterização inicial das dez nascentes estudadas na Bacia Hidrográfica do Rio Turvo Limpo, MG demonstrou uma grande diversidade e algumas destas características estão apresentadas de forma resumida na Tabela 7. 
Tabela 7 - Resumo das características levantadas em dez nascentes da Bacia Hidrográfica do Rio Turvo Limpo, MG

\begin{tabular}{|c|c|c|c|c|}
\hline Nascente & Município & Origem & $\begin{array}{c}\text { Estado de } \\
\text { Conservação 2008 }\end{array}$ & $\begin{array}{c}\text { Vazão média da } \\
\text { nascente (L.h } \text { (1) }^{-1}\end{array}$ \\
\hline 1 & Viçosa & Difusa & Conservada & $24.480,0$ \\
\hline 2 & Porto Firme & Pontual & Conservada & 180,0 \\
\hline 3 & Porto Firme & Difusa & Conservada & $1.008,0$ \\
\hline 4 & Porto Firme & Difusa & Conservada & $5.724,0$ \\
\hline 5 & Porto Firme & Difusa & Perturbada & $43.020,0$ \\
\hline 6 & Viçosa & Difusa & Conservada & 396,0 \\
\hline 7 & Viçosa & Difusa & Perturbada & $13.464,0$ \\
\hline 8 & Porto Firme & Difusa & Perturbada & $3.888,0$ \\
\hline 9 & Viçosa & Difusa & Perturbada & $1.656,0$ \\
\hline 10 & Viçosa & Pontual & Perturbada & 612,0 \\
\hline
\end{tabular}

\section{Conclusões}

As nascentes localizadas nas dez propriedades rurais da Bacia Hidrográfica do Rio Turvo Limpo se apresentam como grandes produtoras de água para a Bacia Hidrográfica do Rio Turvo Limpo e, consequentemente para a Bacia Hidrográfica do Rio Doce, MG. Entretanto, o uso e ocupação do solo nas microbacias onde estas nascentes estão inseridas influenciam diretamente os processos hidrológicos e podem afetar a quantidade e qualidade dos recursos hídricos locais. Mesmo com a implantação de técnicas conservacionistas de água e solo nas áreas de contribuição das nascentes estudadas percebe-se que a qualidade da água está comprometida pela presença de coliformes totais. Acredita-se que o processo de recuperação seja lento e espera-se que com o passar dos anos, através do manejo adequado destas bacias, estas águas apresentem parâmetros microbiológicos mais satisfatórios.

\section{Referências Bibliográficas}

AGÊNCIA NACIONAL DE ÁGUAS - ANA. Divisão Hidrográfica Nacional. Disponível em: $<$ http://www.ana.gov.br/mapainicial/pgMapal.asp>. Acesso em: 20 jan. 2009.

BRASIL. Resolução CONAMA No 357, 17 mar. 2005. Dispõe sobre a classificação dos corpos de água e diretrizes ambientais para o seu enquadramento, bem como estabelece as condições e padrões de lançamento de efluentes, e dá outras providências. Brasília: Ministério do Meio Ambiente/Conselho Nacional de Meio Ambiente. 2005.

BRASIL. Portaria $\mathbf{N}^{\mathbf{0}} \mathbf{5 1 8}, 25$ mar. 2004. Estabelece os procedimentos e responsabilidades relativos ao controle e vigilância da qualidade da água para consumo humano e seu padrão de potabilidade, e dá outras providências. Brasília, DF: Ministério da Saúde. 2004.

FERNANDES, M.M. Caracterização de Solos e Uso Atual Empregando Aerofotos Não-Convencionais nas Sub-Bacias Marengo, Palmital e Silibar - Rio Turvo Sujo, MG. 1996. 98f.. Dissertação (Mestrado em Solos e Nutrição de Plantas) - Universidade Federal de Viçosa. Viçosa, MG.

IGAM - INSTITUTO MINEIRO DE GESTÃO DAS ÁGUAS. Monitoramento da qualidade das águas superficiais na Bacia do Rio Doce em 2007. Belo Horizonte: Instituto Mineiro de Gestão das Águas, dezembro, 2008. 171p. Disponível em: <http://www.igam.mg.gov.br> . Acesso em: 30 jan. 2009.

SANTOS, G. V.; DIAS, H. C. T.; SILVA, A. P. de S.; MACEDO, M. de N. C. de. Análise hidrológica e socioambiental da bacia hidrográfica do córrego Romão dos Reis, Viçosa-MG. Revista Árvore, v. 31, n.5, p. 931-940, 2007.

VIANELLO, R. L.; ALVES, A. R. Meteorologia básica e aplicações. Viçosa-MG: UFV, 1991. 448 p. 